\title{
Novel approaches for identifying target antigens of autoreactive human $B$ and $T$ cells
}

\author{
Klaus Dornmair • Edgar Meinl • Reinhard Hohlfeld
}

Received: 17 April 2009/Accepted: 13 August 2009/Published online: 11 September 2009

(C) Springer-Verlag 2009

\begin{abstract}
Antigen-specific immune responses in multiple sclerosis have been studied for decades, but the target antigens of the putatively autoaggressive $\mathrm{B}$ and $\mathrm{T}$ cells still remain elusive. Here, we summarize recent strategies which are based on the direct analysis of biopsy or autopsy specimens from patients. Since this material is extremely scarce, the experimental methods need to be exceptionally sensitive. We describe technologies to distinguish (auto) aggressive $\mathrm{T}$ cells from irrelevant bystander lymphocytes by analyzing clonal expansions in relation to the morphological location of the cells in the tissue lesions. We then discuss approaches to clone matching $\alpha$ - and $\beta$-chains of the antigen-specific $\mathrm{T}$ cell receptor (TCR) molecules from single $\mathrm{T}$ cells. This is necessary because usually, several clones are expanded and are diluted by many irrelevant cells. The matching TCR chains from individual T cells can be resurrected in hybridoma cells which may then be used for antigen searches. We discuss strategies to identify antigens of $\gamma \delta$ - and $\alpha \beta$-TCR molecules, such as biochemical methods, candidate antigens, human leukocyte antigen requirements, synthetic peptide, and cDNA libraries. These strategies are tailored to characterize the antigens of the membrane-anchored, low-affinity TCR molecules. The strategies to identify (auto) reactive B cells or immuno-
\end{abstract}

K. Dornmair $\cdot$ E. Meinl $\cdot$ R. Hohlfeld

Department of Neuroimmunology,

Max-Planck-Institute of Neurobiology,

Am Klopferspitz 18,

82152 Martinsried, Germany

K. Dornmair $(\bowtie) \cdot$ E. Meinl $\cdot$ R. Hohlfeld

Institute of Clinical Neuroimmunology,

Ludwig Maximilians University,

Klinikum Grosshadern, Marchioninistr. 15,

81366 Munich, Germany

e-mail: dornmair@neuro.mpg.de globulin (Ig) molecules are fundamentally different, because Ig molecules are water-soluble and have high affinities. We further discuss proteome-based approaches, techniques that analyze Ig-chains from single B cells, and a repertoire-based method that compares Ig-proteomes and Ig-transcriptomes. The first method detects Ig antigens directly, whereas the latter two methods allow reconstruction of Ig molecules, which can be used for antigen searches.

Keywords Autoimmunity · Multiple sclerosis .

T cell receptor $\cdot \mathrm{B}$ cells $\cdot$ Immunoglobulins

\section{Introduction}

The current concepts of multiple sclerosis (MS) as an autoimmune disease are mainly based on the animal model "experimental autoimmune encephalomyelitis" (EAE) [1, 2]. In different EAE models, several distinct molecularly defined antigens could be demonstrated to induce pathogenic $\mathrm{T}$ and/or $\mathrm{B}$ cell responses. However, the target antigen(s) recognized by immune cells in the different forms of human MS still remain speculative. In the past, most investigations of putatively pathogenic human B- and $\mathrm{T}$ cells relied mainly on blood as the most easily accessible source. Obviously, this is far from ideal, because any relevant cells are (a) remote from the target tissue, (b) heavily diluted with irrelevant cells, and (c) likely to have phenotypical and functional properties completely different from the tissue-infiltrating cells. Most importantly, all investigations of isolated circulating or migrating cells necessarily lack crucial morphological information on how the cells interact with the surrounding tissue. The most direct approach would of course be to focus on the 
autoimmune target tissue as the most valuable source of information. This approach is far from trivial, because it demands a set of new techniques for obtaining maximum information from scarce human autopsy and biopsy material.

The central problem of such a direct strategy is the availability of tissue samples. For most diseases, wellpreserved biopsy specimens are extremely rare. For example, brain or spinal cord lesions are usually not biopsied in MS patients. The same holds true for pancreas samples of type I diabetes patients, etc. There are only few autoimmune diseases where diagnostic biopsies are taken on a regular basis. One such example is provided by the inflammatory myopathies (IM). This situation contrasts with animal experiments, where diseases may be induced and manipulated experimentally, and where tissue samples may be collected at any time point of choice, even at preclinical stages.

For many years, we have investigated antigen-directed immune responses in MS and IM target tissues, that is, brain and muscle. Both in MS and IM, T cells - especially CD8+ cells - infiltrate the organs. It is not known how these cells are attracted or how the local inflammatory response is sustained. The target antigens are also unknown. The B cell responses, i.e., the (auto) antibody responses, are somewhat better understood. This is mainly due to the fact that soluble immunoglobulin (Ig) proteins are easier to investigate than autoaggressive $\mathrm{T}$ cells where the autoaggressive $\mathrm{T}$ cell receptor (TCR) is a member of a multimeric complex of membrane proteins. During the course of our studies, we have developed a series of technologies that allow analysis of $\mathrm{T}$ and $\mathrm{B}$ cell responses in IM and MS.

Our main long-term goal is to identify the target antigens recognized by tissue-infiltrating $\mathrm{T}$ and $\mathrm{B}$ cells in MS and IM [3]. With very few exceptions, these target antigens are

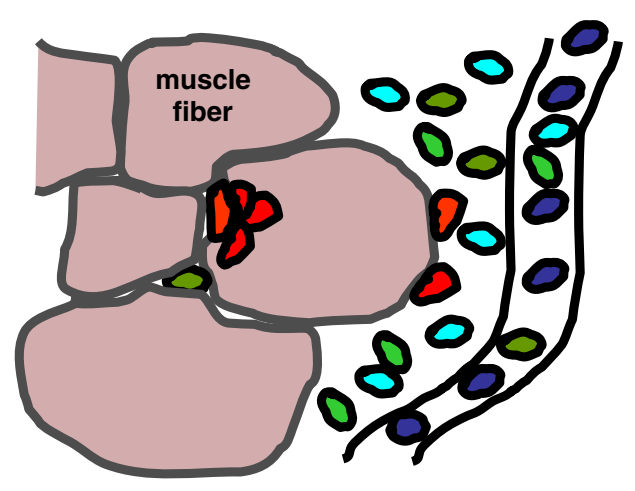

Fig. 1 Autoaggressive T cells attack muscle fibers. In the schematic representation (left) the autoaggressive T cells are shown in red. Many other bystander $\mathrm{T}$ cells and $\mathrm{T}$ cells in blood vessels are present in the same tissue (blue and green). On the right panel, we show an immunohistochemical stained cryosection from the muscle of a PM unknown. This is unfortunate, because knowing the target antigens would be of great help for developing diagnostic markers and immunotherapies. To achieve this goal, many obstacles need to be overcome: Firstly, well-preserved tissue, especially brain biopsy material, is very rare. Secondly, putatively autoreactive $\mathrm{T}$ cells and B cells must be distinguished from bystander cells (Fig. 1). Therefore, morphological analysis followed by microdissection and single cell polymerase chain reaction (PCR) is required, which is, thirdly, particularly difficult owing to the extremely low RNA concentrations. Fourthly, the antigenspecific TCR and Ig molecules are both composed of various genetic elements, containing hypervariable regions and mutations. Therefore, multiplex PCR must be employed. Fifthly, the search for antigens is not trivial because huge libraries must be screened. This is particularly difficult for $\mathrm{T}$ cells, because the notoriously low affinities of TCR-antigen interactions [4-7] impede straightforward biochemical methods.

The first step of our analysis is the identification of cell clones or Ig molecules that are expanded in the target tissue, driven by antigen recognition. Such "repertoire studies" help us to distinguish between pathogenic and irrelevant cells or molecules. In the next step, we focus on individual $\mathrm{T}$ cells and their antigen-specific receptor, or on clonally expanded antibodies. We then amplify the TCR or Ig chains by PCR and express them in vitro. The transfectants are then used for antigen searches. In a first series of experiments, "best guess" candidate antigens may be screened. Such candidates usually come from animal experiments. A more unbiased approach is to screen cDNA expression libraries. The cDNA libraries may be generated from the affected organs, or-preferred-from the biopsy specimen of the patient. Depending on whether B or T cell antigens are investigated, the libraries are either expressed and screened directly or must be introduced into the class-I

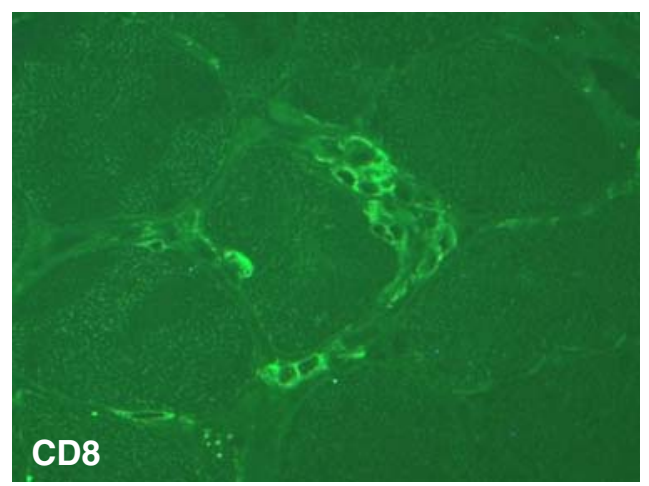

patient. CD8 $+\mathrm{T}$ cells are stained in green. In the scheme and in the cryosection, muscle-attached single $\mathrm{T}$ cells and $\mathrm{T}$ cell clusters that focally invade the muscle fibers are seen (modified from [23] with permission) 
or class-II major histocompatibility complex (MHC) presentation pathway before they are screened.

Here, we will review the current state of antigen detection efforts in MS research. Both, for B cell and for $\mathrm{T}$ cell antigens, several technical challenges have to be overcome. Since the experimental strategies for identifying $\mathrm{B}$ and $\mathrm{T}$ cell antigens are quite different, we will discuss the respective approaches separately. Needless to say, these new techniques may also be applied to tissues from patients with other autoimmune, neoplastic, or inflammatory diseases where adaptive immune responses occur.

\section{$T$ cell antigens}

TCR repertoire in autoimmune tissue lesions

Tissue-infiltrating $\mathrm{T}$ cells are observed in all patients with MS or IM. In most cases, the T cell infiltrates are composed of $\alpha \beta-\mathrm{T}$ cells, whereas $\gamma \delta$-T cells are rather an exception [8-10]. In MS, CD8+ T cells usually outnumber the CD4+ population [11]. In IM, it depends on the subtype of the disease: While in inclusion body myositis and polymyositis, CD8+ T cells clearly dominate, while CD4+ T cells are more prominent in dermatomyositis $[12,13]$. We have intensively studied the $\alpha \beta$-TCR repertoire of infiltrating $\mathrm{CD} 8+\mathrm{T}$ cells in MS brain specimens [14-16] and in myositis muscle tissue of polymyositis and inclusion body myositis patients [17-19]. Using CDR3-spectratyping, we found that in these diseases, CD8+ T cells are expanded in the target tissues and blood, and that these expanded clones may persist for many years in some patients. We investigated the TCR repertoire in muscle samples and blood of several patients with IM [19] and in brain tissue, cerebrospinal fluid (CSF), and blood of MS patients [15]. In the myositis study, we identified expanded $\mathrm{T}$ cell clones in muscle biopsy tissue of ten patients. From four patients, we isolated single, morphologically characterized $\mathrm{T}$ cells by laser microdissection and analyzed the TCR $\beta$-chains by single cell PCR. These $T$ cells were most probably autoaggressive, because they belonged to expanded clones, were in direct contact with their target cells, and carried silent nucleotide exchanges in the TCR CDR3-N-regions. This indicates that the clonal expansions were driven by particular antigen(s). Expanded clones were not only detectable in muscle tissue but also in the $\mathrm{CD} 8+\mathrm{T}$ cell compartment of peripheral blood, where they persisted for many years. Persistent CD8 $+\mathrm{T}$ cell clones were also detected in MS patients [15]. We found that these CD8+ clones were also present in brain tissue, CSF, and peripheral blood. By contrast, the $\mathrm{CD} 4+$ population was polyclonal. Strikingly, some of the CD8+ T cells that had been identified in brain tissue persisted in peripheral blood and
CSF for more than 7 years. These repertoire studies were the basis of a general strategy that leads to the molecular characterization of $\alpha \beta$-TCR molecules from autoaggressive $\mathrm{T}$ cell [3].

More recently, we compared the TCR repertoires in distinct lesions and in "normal appearing white matter" regions of human autopsy brains from MS patients [16]. Using CDR3-spectratyping, we identified several pervasive $\mathrm{T}$ cell clones in anatomically distant brain lesions, but we did not find any significant differences between lesions and normal appearing white matter. Strikingly, we found silent nucleotide exchanges in some clones, hinting to antigendriven clonal $\mathrm{T}$ cell selection. By combining immunohistochemistry, laser microdissection, and single cell PCR, we could attribute some of these clones to the CD8+ population (Fig. 2). Such expanded clones are excellent candidates for investigating the corresponding TCR $\alpha$ chains, which is a prerequisite for subsequent antigen searches.

This technology is highly valuable not only for investigating $\mathrm{T}$ cell expansions in autoimmune diseases but may also be applied to infections and tumors. For example, we detected several expanded CD8 $+\mathrm{T}$ cell clones in herpes simplex virus-infected human trigeminal ganglia, pointing to an antigen-driven immune response [20]. Furthermore, we identified identical $\mathrm{T}$ cell clones in tumor tissue and in CSF of a patient with paraneoplastic encephalomyelitis. Notably, silent nucleotide exchanges in the CDR3-N-region suggested that the $\mathrm{T}$ cell response in the tumor and in the nervous tissue was directed against a shared antigen, linking the (protective) anti-tumor response and the (adverse) paraneoplastic response against nervous tissue [21]. Further, we identified expanded CD8 $+\mathrm{T}$ cell clones in brain specimens of patients with Rasmussen encephalitis suggesting antigen-driven proliferation [22].

Identification and in vitro "resurrection" of tissue-infiltrating $\mathrm{T}$ cells

In most cases, it is virtually impossible to obtain viable autoaggressive $\mathrm{T}$ or $\mathrm{B}$ cells from biopsy specimens. The first obvious reason is that most available biopsy samples are stored frozen and therefore contain only dead cells. Even if it were possible to obtain a biopsy sample directly after its excision, it would be very difficult to distinguish in the fresh tissue the putatively autoaggressive $\mathrm{T}$ cells from cells that were attracted as bystanders or are present in blood vessels near the inflammatory lesion (Fig. 1). To distinguish between relevant and irrelevant cells, it would be necessary to stain for activation markers and to apply morphological criteria. Next, it would be very difficult to isolate single living cells from such a tissue specimens and to subsequently expand them at a large scale. Such 
Fig. 2 Some of the expanded T cells clones in the brain tissue of multiple sclerosis patients belong to the CD8+ compartment. We detected expanded $\mathrm{T}$ cell clones by CDR3-spectratyping and sequencing of the polymerase chain reaction products (upper panel). Identical sequences were detected in single $\mathrm{T}$ cells that were stained by antiCD8-antibodies and isolated by laser microdissection from cryosections (lower panel; modified from [16] with permission)

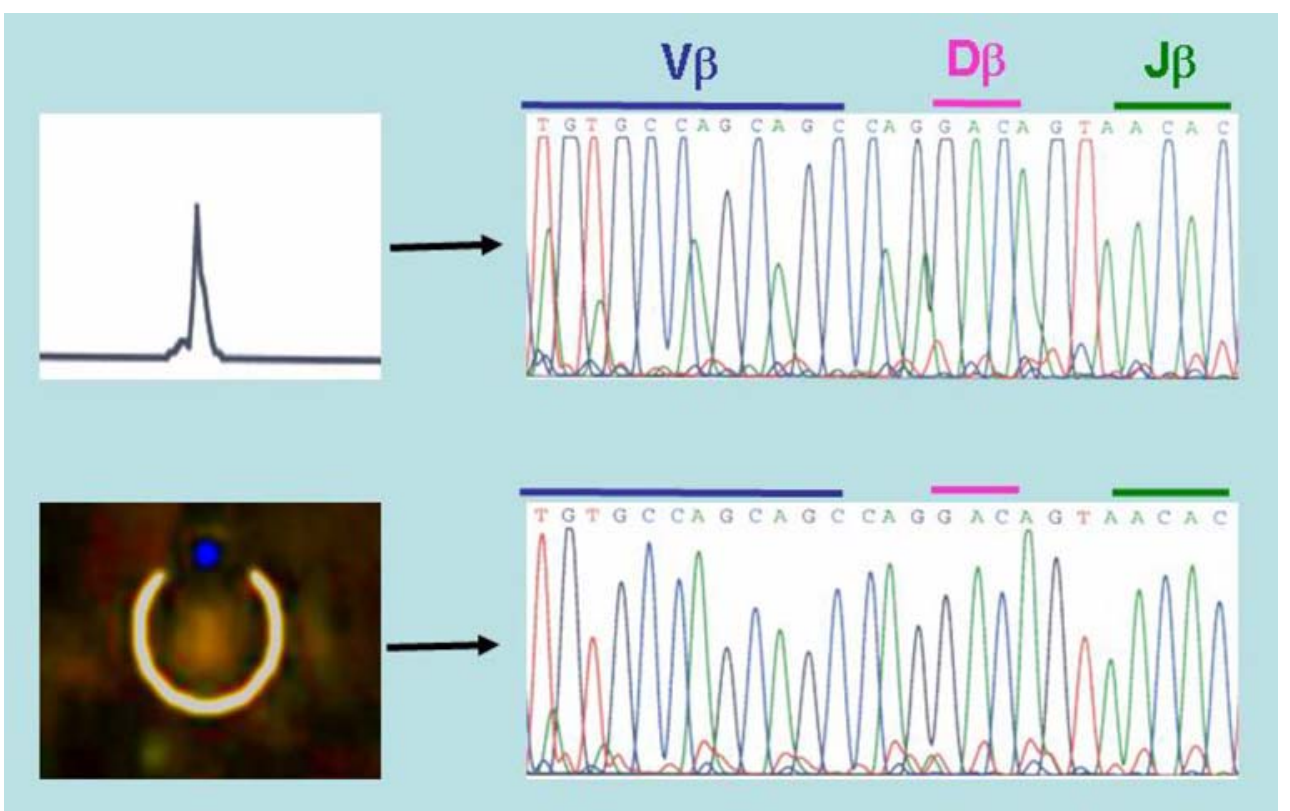

expansion would be necessary because many millions of cells are required to screen the huge libraries for antigen detection (see below). In summary, it will only be possible under exceptional circumstances to use "real" $\mathrm{T}$ or B cells directly from tissue of patients with autoimmune diseases. The situation may be different in some tumors, where big tissue samples are more readily available.

A feasible alternative is the recombinant expression of the antigen-specific receptors that were detected "at the crime scene" in a frozen tissue sample. Based on the repertoire studies described above, we have developed an experimental strategy allowing us to identify paired TCR $\alpha$ - and $\beta$-chains from single cells isolated by laser microdissection from cryosections (Fig. 3) [23]. Detection of TCR $\alpha$-chains has previously been difficult, because TCR $\alpha$-chain genes contain more elements than $\beta$-chain genes [24], and because only very few anti- $\alpha$-chain antibodies are available for immunohistological staining. We distinguish putatively autoaggressive $T$ cells from irrelevant bystander cells by two criteria: First, we screen for clonally expanded TCR $\beta$-chains by CDR3spectratyping, because we assume that putatively autoaggressive populations are expanded in situ. Second, we identify $\mathrm{T}$ cells showing morphological features of autoaggressive behavior by immunohistochemistry. Since we know from the CDR3-spectratyping experiments which TCR $\beta$-chains are expanded in situ, we use antibodies that recognize this particular $\mathrm{V} \beta$-region. Candidate cells that fulfill both criteria are isolated by laser microdissection. To identify matching $\alpha$ - and $\beta$-chains, we apply a new multiplex PCR protocol which allows the unbiased amplification of both TCR chains from single $\mathrm{T}$ cells isolated from cryosections. The first step is to confirm that the cell under question not only carries the correct $\mathrm{V} \beta$-element but also the correct $\mathrm{N}(\mathrm{D}) \mathrm{N}$ - and J-sequences. To this end, we amplify the TCR $\beta$-chain cDNA using clone-specific primers based on the sequences identified by spectratyping. If such a relevant sequence can be confirmed, we detect the matching $\alpha$-chain using a universal $\alpha$-primer set that allows amplification of every possible $\alpha$-chain. Such a multiplex PCR is of course not as sensitive as a PCR reaction with clone-specific primers. Therefore, we re-examine all $\beta$ chain positive T cells where no $\alpha$-chain has initially been detected with the universal primer set. For this additional screen, we use highly efficient clone-specific primers that

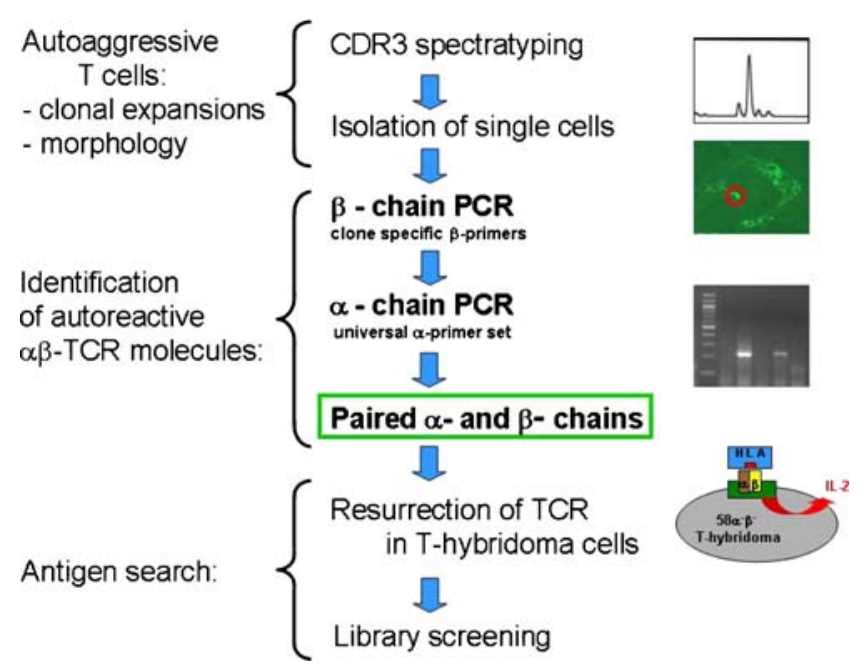

Fig. 3 Strategy for the identification of the target antigens of tissueinfiltrating autoaggressive $\mathrm{T}$ cells. The protocol may not only be applied to autoimmune diseases but also to other types of inflammatory lesions, including tumors and transplants (modified from [23] with permission) 
are based on the surmised $\alpha$-chain sequences. Because this PCR protocol yields only fragments of the TCR chains, the full-length clones must next be reconstructed. Although laborious, this is basically achieved by standard molecular biology techniques. The reconstructed chains are then inserted into an expression vector and transfected into the $\mathrm{T}$ hybridoma cell line $58 \alpha^{-} \beta^{-}[25,26]$ which lacks endogenous TCR chains but carries all CD3 molecules and the machinery to secrete interleukine- 2 after TCR stimulation. The transfected cells can then be used to search for the antigens. Thus, we have essentially "revived" the putatively autoaggressive $\mathrm{T}$ cells that were originally observed in "dead" tissue [23]. In the meantime, we have successfully applied this technology not only to polymyositis and inclusion body myositis but also to MS and other diseases.

So far, we have identified one $\gamma \delta$ - and eight $\alpha \beta$-TCRs from muscle biopsy specimens of myositis patients. We started these studies with samples from myositis patients, because diagnostic tissue specimens were readily available. In one patient, we found four structurally closely related $\alpha$ chains associated with identical $\beta$-chains. One of the $\alpha$ chains was found much more often than the others indicating a dominant expansion. Recently, we have identified four $\alpha \beta$-TCRs from the brain biopsy sample of the MS patient who has been studied extensively by single cell PCR and CDR3 spectratyping $[14,15]$. The TCR $\beta$ chain of the four clones is identical. The $\alpha$-chains have identical V-regions (which code for two of the three complementarity determining regions (CDR1 and 2)). Therefore, five of the six CDR regions which contact the antigen are identical. Strikingly, the N-regions which code for the CDR3-region of the four $\alpha$-chains are different, but highly homologous. This definitely excludes PCR contaminations or cloning artifacts. In one myositis and in one MS patient, we identified a dominant $\mathrm{T}$ cell clone that is accompanied by several other subdominant clones carrying structurally closely related TCRs. Although the clones have an ontogenetically different background, their expansion might have been driven by a common antigen. This interpretation is supported by a recent study of clonal $\mathrm{T}$ cell expansions in a patient with a paraneoplastic neurological disease where, again, ontogenetically different but structurally identical TCR $\beta$-chains were observed in blood, tumor, and nervous tissue [21].

Strategies for identification of $\mathrm{T}$ cell target antigens

\section{$\gamma \delta$-TCR antigens}

The first TCR that we revived was a $\gamma \delta$-TCR from a muscle biopsy specimen of a polymyositis patient [8]. The unique feature of this case was the monoclonal character of
T cell expansion [27]. This allowed us to clone both TCR chains by conventional PCR techniques. We expressed the $\gamma \delta$-TCR on the surface of the T hybridoma cell line $58 \alpha^{-} \beta^{-}$and used the transfectants for characterization of the unknown target antigens $[28,29]$. Identification of the target antigens of $\gamma \delta$-TCRs is particularly difficult because $\gamma \delta$-TCRs are not MHC restricted. Instead, they may recognize the entire spectrum of chemicals, including low molecular weight compounds that are immobilized by proteins [30-33]. Strikingly, the affinity of $\gamma \delta$-TCRs to their targets is very low. Therefore, biochemical methods such as immunoprecipitation or affinity chromatography, which are most efficient for detecting the ligands of Ig or receptors (except TCRs), are not applicable. For this reason, the protein(s) that present alkyl phosphates to the most prevalent human $\gamma \delta$-TCR subset, the $\mathrm{V} \gamma 9 \mathrm{~V} \delta 2 \mathrm{~T}$ cells, are still not known [34]. By classical biochemical methods, we have gathered a substantial amount of information on the properties of the target antigen(s): it is expressed in the cytosol of the target cells, it is water-soluble, has a molecular mass greater than $8 \mathrm{kDa}$, and contains a protein moiety [29]. Most recently, we have gained preliminary evidence that proteins involved in RNA translation are the molecular targets of our $\gamma \delta$-TCR. These proteins express a common motif which is conserved through many species from man to bacteria. This is consistent with a molecular mimicry-like mechanism of induction of autoimmunity ([35-37].

\section{$\alpha \beta$-TCR antigens: HLA-requirements and candidate antigens}

All $\alpha \beta$-TCR molecules depend on the presentation of antigenic peptides by their relevant human leukocyte antigen (HLA) restriction molecule. When a particular TCR is cloned from a tissue sample, it is a priori not known which of the HLA molecules of the patient is required for antigen presentation. For each $\mathrm{CD} 8+$ or CD4+ $\mathrm{T}$ cell, any one of the six class-I or class-II molecules may be the correct candidate. Ideally, one would therefore like to use autologous professional antigen presenting cells (APC) from the investigated patient. However, even if original tissue or blood of the patient were available, it would presumably be difficult to generate sufficient numbers of autologous dendritic cells, macrophages, or other professional APCs from such limited sources. As an alternative, Epstein-Barr virus transformed B cell line may be generated from the patient's blood, but such cell lines are non-adherent, grow in big clusters, and are difficult to transfect. They are therefore not very well suited as recipient cells for huge libraries, where a high transfection efficiency is required. Not many alternatives remain, except for determining the HLA alleles of the patients by standard 
techniques and then co-transfecting them together with cDNA libraries into immortalized cell lines. This was indeed the way how the first $\mathrm{T}$ cell antigens of tumors were identified [38]. By contrast, in animals, where tissue supply is virtually unlimited, things are less complicated: tissue can be fractionated by biochemical methods and presented by autologous APCs until the antigen(s) are finally characterized [39].

In some diseases, there are candidate antigens that may be tested as a "best guess". For MS, there are several candidates, all of which come from the animal model EAE. Examples include myelin basic protein, proteolipid protein, myelin oligodendrocyte glycoprotein, S100ß, neurofascin, neurofilament, and aquaporin-4. Some of them are available as proteins purified from human brain or as recombinant proteins. In case of $\mathrm{CD} 4+\mathrm{T}$ cells, the candidate antigens may just be added to APCs, which take them up, digest them in their lysosomes, and present them on their HLA class-II molecules. In case of CD8+ T cells, things are more complicated: Peptides or proteins that are added to the cells from the outside will reach class-I MHC molecules only if dendritic cells are used as APCs, because dendritic cells are the only cell type that is capable of cross-presentation [40, 41]. All other cell types direct external antigens almost exclusively onto class-II MHC molecules. Dendritic cells, however, are available only in very limited amounts and can not be expanded into high cell numbers. This considerably limits their usage. The best way to direct antigens onto class-I HLA molecules is transfection of their coding DNA into APCs. To this end, the cDNAs of the candidate antigens need to be cloned and inserted into a suitable plasmid or viral vector, which is of course laborious and time consuming.

\section{$\alpha \beta$-TCR antigens: combinatorial peptide libraries}

A versatile and efficient method may be the use of positional scanning synthetic combinatorial peptide libraries (PS-SCL) [42-44]. The idea behind these libraries is that TCR molecules recognize patterns rather than defined sequences or structures. In other words, the recognition of target structures is polyspecific, promiscuous, and degenerate [45]. Therefore, it is often observed that some amino acids of a given peptide may be substituted by chemically similar amino acids. In some cases, even very different amino acids may be substituted without loss of TCR recognition. PS-SCL therefore contain random amino acids in all but one position of the peptide. The one position that is fixed is successively occupied with one defined amino acid. Randomization is achieved by introducing all 20 possible amino acids simultaneously during peptide synthesis. A library of 9 mer peptides therefore consists of $9 \times 20=180$ different randomized peptide pools. For comparison, synthesis of all possible 9mer peptides would require $20^{9}=0.5 \times 10^{12}$ different individual peptides.

For evaluation of TCR recognition motifs, the randomized peptide pools are presented by appropriate APCs to the TCRs. In the example given above, 180 tests must be run. TCR activation will be observed whenever a relevant amino acid fits to the TCR recognition motif, for example, a positive charge at position 2 , an aromatic amino acid at position 5, and small amino acids at positions 4 and 9 . Several peptide pools are usually recognized, and altogether, they provide the TCR recognition motif, which may then be searched for in databases of existing proteins [43]. The search may or may not be limited to databases from particular species, such as human or microbial proteins. Finally, candidate peptides are synthesized and tested individually.

\section{$\alpha \beta$-TCR antigens: $c D N A$ libraries}

Since the seminal studies of Van der Bruggen et al. [38], a number of tumor antigens have been identified by screening of cDNA libraries [46, 47]. Many studies followed the original experimental concept where a cDNA library from tumor tissue was cloned into a plasmid that contained the SV40 origin of replication. These plasmids were cotransfected together with the appropriate HLA molecules into COS cells, where they are amplified and they produce the putative antigens. The plasmids can be recovered from positive APCs so that the inserts may be identified by sequence analysis. An alternative method uses a viral vector which also allows plasmid recovery and sequence analysis [48]. Screening of a cDNA library has revealed autoantigens in a diabetes mouse model [49], but so far, no antigens from human autoimmune diseases have been identified.

The choice of the library is critical, for which several alternatives exist. First, tissue-specific libraries may be generated or purchased from various suppliers. Although this is the most convenient, the disadvantages are clear: These libraries do not contain any patient- or diseasespecific peculiarities or polymorphisms. Further, the distribution of transcripts is heavily biased, and rare transcript is highly diluted. Second, "normalization" of libraries may overcome the latter disadvantage. Normalization means that the most abundant transcripts are reduced in number through a series of hybridization steps. This method requires high amounts of cDNA to start with and is technically far from trivial. Third, cDNA may be extracted from tissue of patients. Such a library would contain all the patient- and disease-specific polymorphisms (including viral transcripts), but clearly, such material is scarce. A further disadvantage is that whole biopsy tissue still contains many different cell types, not only the cells that are targeted by the autoimmune attack. A fourth, technically challenging type of library is the subtraction library. Here, 
disease-related transcripts are strongly overrepresented. Such libraries are generated by cloning only the cDNAs that are differentially expressed between two tissues. An excess of RNA from one tissue is immobilized on a solid surface, cDNA from another tissue is hybridized, and the non-hybridizing transcripts are collected. They are then cloned into expression vectors which are used to transfect suitable APCs. Subtraction libraries require high amounts of material. Although T7 promoter-based linear RNA amplification kits [50] are meanwhile available from several commercial sources, there are still problems obtaining enough full-length products. Note that for many applications, such as analysis by microarrays or quantitative PCR, short, incomplete sequences are often sufficient, whereas expression cloning requires full-length sequences with intact, in-frame translation start codons.

\section{B cell antigens}

The role of B cells in MS is increasingly appreciated [51]. The search for B cell antigens may be conducted by using serum samples or other body fluids that contain relatively high amounts of (auto) antibodies. This is a big advantage as compared to investigating $\mathrm{T}$ cell antigens, because cloning of Ig chains from single cells is not necessarily required, although the latter approach might also be an option. We will discuss here three different approaches to analyze B cell (auto) antigens: The first is a proteomicbased strategy where brain tissue is fractionated, the putative antigens are separated by 2-d gel electrophoresis, and screened with patient's sera. This resulted in the identification of the two axoglial antigens neurofascin and contactin-2/TAG-1 as novel targets of autoantibodies of MS patients. Testing the functional relevance of an autoimmune response against these two novel autoantigens revealed that antibodies to neurofascin specifically target the node of Ranvier and induce an axonal injury [52], and that a $\mathrm{T}$ cellular response against contactin-2 induced gray matter lesions [53]. The second approach is comparable to the strategy for the identification of putatively autoaggressive $\mathrm{T}$ cells discussed above: single B- or plasma cells are excised from tissue sections, the Ig chains are analyzed, and recombinant Ig molecules are used for antigen searches. The third strategy makes use of the virtually infinite variability of antibodies that underwent affinity maturation: Ig-mRNA transcriptomes are established from CSF of patients and compared to the Ig-proteome, which is determined independently from the same tissue by mass spectrometry. This allowed us to match the Ig-transcriptomes and -proteomes of the so-called "oligoclonal bands" (OCBs) of MS patients [54]. These experiments provided evidence that B lineage cells are able to synthesize the OCBs and allowed us to identify and reconstruct Ig molecules that constitute the OCBs.

\section{Proteome-based approach}

This strategy is based on a separation of different protein preparations from the brain by $2 \mathrm{D}$ gel electrophoresis and subsequent identification of the proteins that are recognized by MS patients sera with a subsequent Western blot and mass spectrometry. To follow this line, we first focused on myelin glycoproteins as potential targets. This focusing on glycoproteins has two reasons. First, glycoproteins are quantitatively minor components, and enrichment of glycoproteins greatly enhances the sensitivity for detection of antibodies against them [53]. Second, glycoproteins are expected to be largely at the outer surface and should therefore be easily accessible to antibodies. With this approach, we could identify the two neuronal-glial antigens neurofascin and contactin-2/TAG-1 as novel targets of autoantibodies of MS patients. Neurofascin exists in two isoforms: NF186 is a neuronal protein concentrated in myelinated fibers at nodes of Ranvier, and NF155 is the oligodendrocyte-specific isoform of neurofascin concentrated at the paranodes. To evaluate whether circulating antineurofascin antibodies mediate a pathogenic effect in vivo, we co-transferred these antibodies with myelin oligodendrocyte glycoprotein-specific encephalitogenic $\mathrm{T}$ cells to mimic the inflammatory pathology of MS and breach the blood-brain barrier. In this animal model, antibodies to neurofascin selectively targeted nodes of Ranvier, resulting in deposition of complement, axonal injury, and disease exacerbation [52]. Together, we have identified a novel mechanism of immune-mediated axonal injury. The relevance for the axonal pathology in MS needs to be elaborated.

The second novel target of autoantibodies that we could identify with this approach is contactin-2/TAG-1 [53]. Contactin-2 and its rat homologue TAG-1 (transiently expressed axonal glycoprotein-1) are expressed by various neuronal populations and sequestered in the juxtaparanodal domain of myelinated axons both at the axonal and myelin side. We found that MS patients mount both autoantibodies and Th1/Th17 $\mathrm{T}$ cell responses specific for contactin-2. The pathogenic significance of these autoimmune responses was then explored in EAE models in the rat. Adoptive transfer of TAG-1 specific $T$ cells induced an encephalitis characterized by a preferential inflammation of gray matter of the spinal cord and cortex. Co-transfer of TAG-1-specific T cells with a myelin oligodendrocyte glycoprotein-specific $\mathrm{mAb}$ generated focal perivascular demyelinating lesions in the cortex and extensive demyelination in spinal cord gray and white matter. This study identifies contactin- 2 as a novel autoantigen targeted by $\mathrm{T}$ cells and autoantibodies in MS. Our findings suggest that a contactin-2-specific $\mathrm{T}$ cell 
response contributes to the development of gray matter pathology.

\section{B cell-based approach}

Similar to the analysis of single T cells, strategies have been developed to analyze antibodies produced by single cells of the B linage. Again, the morphology of the tissue lesion is a main criterion to discriminate between irrelevant and potentially relevant cells, and therefore, again, multiplex single cell analysis is required. A number of protocols for amplification of matching heavy and light chain cDNA from single B- or plasma cells have been described [5559], and many expression systems are suited to produce recombinant single-chain Fv molecules, Fab fragments, or whole antibodies for a variety of purposes [60]. However, no antigens have so far been identified that are recognized by antibodies detected in single B- or plasma cells isolated from brain or muscle specimens [61-63]. This is particularly surprising because most Ig chains amplified from tissue lesion are of the IgG1 family and contain many somatic hypermutations. Therefore, they should bind their antigens with relatively high affinity. This would be a major prerequisite for employing established antigen identification techniques such as immunoprecipitation or affinity chromatography, or more recent and elaborate techniques such as screening of protein or lipid arrays [64-67].

\section{B cell and immunoglobulin repertoires}

Analysis of the CSF has great diagnostic value for inflammatory diseases of the central nervous system, since CSF samples are readily available. In particular, intrathecal antibody production is widely used in the diagnosis of MS. Since its first description in 1942 [68], it is known that CSF antibodies can be visualized as distinct bands in isoelectric focusing gels, the OCBs. OCBs are composed of a limited number of $\mathrm{Ig}$ species. The OCB antibodies belong predominantly to the complement-activating IgG1 family. They have undergone affinity maturation as evident from extensive somatic hypermutation (SHM). Their pattern is typical for each individual patient, and they may persist for very long periods of time, even during immunosuppressive therapy. Altogether, these observations suggest an antigendriven B cell response. Although it has long been known that the OCBs are synthesized intrathecally, it was unknown whether the OCB-producing cells reside in the $\mathrm{CSF}$, in the brain parenchyma, or in the ectopic B cell follicles in the cerebral meninges. Detailed analyses of the Ig transcript repertoires from CSF-resident B cells revealed clonal restrictions ("oligoclonality") and a high degree of SHM [59, 69-73]. Therefore, it was assumed that these B cells might produce the OCBs, but this assumption has never been proven. None of the previously published studies attempted to link the two data sets by analyzing both Ig proteins and transcripts in parallel.

To analyze the antibody repertoires in MS, we developed a new technique for comparing Ig repertoires at the Ig transcript (B cell) and protein (antibody) levels (Fig. 4). We created patient-specific IgG databases from diagnostic CSF samples by analyzing the Ig transcripts of the B cells. In parallel, we analyzed the Ig proteins directly by mass spectrometry. In contrast to traditional analyses, which compare germ line transcriptomes and proteomes, our approach is based on the SHM and hypervariable V(D)J recombination patterns, which are unique to each patient. Thus, we preferentially analyzed "characteristic" peptides, i.e., peptides which contain amino acids introduced by SHM or V(D)J recombination. We analyzed four patients by comparing their CSF Ig-proteomes and transcriptomes and found that the CSF Ig-proteomes match to large extent with the corresponding B cell Ig-transcriptomes. We showed by two independent experiments that this alignment is specific: First, we analyzed all peptides by tandem mass spectrometry. Although this technique usually does not yield results for all peptides tested, we could show for some characteristic peptides that they are indeed patient-specific. Second, we tested the specificity of our alignments by comparing the proteomes of a patient not only to the "correct" transcriptome, i.e., the transcriptome of the very same patient, but also the transcriptome of "incorrect", i.e., other, patients. Both experiments revealed that our alignments were correct. This high concordance demonstrates that the B lineage cells contained in the CSF are indeed a source of the Ig OCBs [54].

A still open question regards the target antigens of OCBs. Several B cell antigens have been described that are



Fig. 4 Comparison of $\mathrm{B}$ cell transcriptome and immunoglobulin proteome from the cerebrospinal fluid (CSF) of multiple sclerosis patients by molecular cloning and mass spectrometry. We found strong overlaps between the transcriptomes and proteomes. This provides evidence that CSF-resident B cells are capable to synthesize the IgGs which constitute the OCBs 
recognized by (auto) antibodies from serum or CSF of MS patients [51], but none of them could be attributed to OCBs. Interestingly, there seems to be an obvious contradiction: On one hand, the OCB antibodies are quantitatively expanded Ig populations, carry extensive SHM, and preferentially belong to the IgG1 family. This provides strong evidence that the producing $\mathrm{B}$ cells had long-lasting contact with their antigens. On the other hand, the OCB are soluble antibodies that are present in high concentrations in the CSF. This means that they are not absorbed by their antigens and/or that their antigens are present in very low concentrations. If so, why are these antigens not removed by various antibody-dependent clearance mechanisms? Our technology for analyzing OCBs may help to address this question. If the paired heavy and light chains from individual bands could be identified, then the paired Ig chains can be expressed recombinantly and used for antigen searches. Because the antibodies have undergone affinity maturation, their affinities are presumably high. This will allow isolation of the antigens by affinity chromatography and their analysis by mass spectrometry. However, the abovementioned correlation is technically not trivial, because the OCBs are always embedded in a pool of polyclonal background of many non-expanded antibodies. Therefore, such an approach would require further Ig purification by 2-D electrophoresis and high-performance liquid chromatography. Its advantage, however, is clear: It focuses directly on OCB proteins. In contrast, the more traditional analysis of antibodies produced by single $\mathrm{B}$ cells does not reveal whether the antibodies belong to OCB.

\section{Outlook}

The new experimental tools that we described here will advance our knowledge of the immunopathogenesis of MS and other neuroimmunological diseases. Moreover, they will help to identify new diagnostic biomarkers, e.g., for identifying disease subtypes and - perhaps - new pathogenetic syndromes. Last but not least, the new techniques have the potential eventually to improve our therapeutic options, e.g., by helping to design "individualized" selective immunotherapies [74].

Acknowledgements This work was supported by the Hermann and Lilly Schilling Stiftung, the Deutsche Forschungsgemeinschaft through grants SFB571-A1 and -C3, and the sixth Framework Program of the European Union NeuroproMiSe LSHM-CT-2005-018637.

\section{References}

1. Steinman L, Zamvil SS (2006) How to successfully apply animal studies in experimental allergic encephalomyelitis to research on multiple sclerosis. Ann Neurol 60:12-21. doi:10. 1002/ana.20913

2. Wekerle H (2008) Lessons from multiple sclerosis: models, concepts, observations. Ann Rheum Dis 67:56-60. doi:10.1136/ ard.2008.098020

3. Dornmair K, Goebels N, Weltzien HU, Wekerle H, Hohlfeld R (2003) T-cell-mediated autoimmunity - novel techniques to characterize autoreactive T-cell receptors. Am J Pathol 163:1215-1226

4. Davis SJ, Ikemizu S, Evans EJ, Fugger L, Bakker TR, Van der Merwe PA (2003) The nature of molecular recognition by T cells. Nat Immunol 4:217-224. doi:10.1038/ni0303-217

5. Krogsgaard M, Davis MM (2005) How T cells 'see' antigen. Nat Immunol 6:239-245. doi:10.1038/ni1173

6. Rudolph MG, Stanfield RL, Wilson IA (2006) How TCRs bind MHC, and coreceptotrs. Annu Rev Immunol 24:419-466. doi:10.1146/annurev.immunol.23.021704.115658

7. Stone JD, Chervin AS, Kranz DM (2009) T-cell receptor binding affinities and kinetics: impact on T-cell activity and specificity. Immunology 126:165-176. doi:10.1111/j.1365-2567.2008.030 15. $\mathrm{x}$

8. Hohlfeld R, Engel AG, Ii K, Harper MC (1991) Polymyositis mediated by $\mathrm{T}$ lymphocytes that express the $\gamma / \delta$ receptor. N Engl J Med 324:877-881

9. Ang S-L, Seidman JG, Peterman GM, Duby AD, Benjamin D, Lee SJ, Hafler DA (1987) Functional lambda chain-associated T cell receptors on cerebrospinal fluid-derived natural killer-like $\mathrm{T}$ cell clones. J Exp Med 165:1453-1458. doi:10.1084/jem.165. 5.1453

10. Wucherpfennig KW, Newcombe J, Li H, Keddy C, Cuzner ML, Hafler DA (1992) $\gamma \delta \mathrm{T}$ cell receptor repertoire in acute multiple sclerosis lesions. Proc Natl Acad Sci U S A 89:4588-4592. doi:10.1073/pnas.89.10.4588

11. Friese MA, Fugger L (2005) Autoreactive CD8+ T cells in multiple sclerosis: a new target for therapy? Brain 128:17471763. doi:10.1093/brain/awh578

12. Dalakas MC (2006) Sporadic inclusion body myositis-diagnosis, pathogenesis and therapeutic strategies. Nat Clin Pract Neurol 2:437-447. doi:10.1038/ncpneuro0261

13. Dalakas MC, Hohlfeld R (2003) Polymyositis and dermatomyositis. Lancet 362:971-982. doi:10.1016/S0140-6736(03)14368-1

14. Babbe H, Roers A, Waisman A, Lassmann H, Goebels N, Hohlfeld R, Friese M, Schröder R, Deckert M, Schmidt S, Ravid R, Rajewsky K (2000) Clonal expansion of $\mathrm{CD}^{+} \mathrm{T}$ cells dominate the $\mathrm{T}$ cell infiltrate in active multiple sclerosis lesions shown by micromanipulation and single cell polymerase chain reaction. J Exp Med 192:393-404. doi:10.1084/jem.192.3.393

15. Skulina C, Schmidt S, Dornmair K, Babbe H, Roers A, Rajewsky K, Wekerle H, Hohlfeld R, Goebels N (2004) Multiple sclerosis: brain-infiltrating $\mathrm{CD} 8^{+} \mathrm{T}$ cells persist as clonal expansions in the cerebrospinal fluid and blood. Proc Natl Acad Sci U S A 101:2428-2433. doi:10.1073/pnas.0308689100

16. Junker A, Ivanidze J, Malotka J, Eiglmeier I, Lassmann H, Wekerle H, Meinl E, Hohlfeld R, Dornmair K (2007) Multiple sclerosis: T-cell receptor expression in distinct brain regions. Brain 130:2789-2799. doi:10.1093/brain/awm214

17. Bender A, Ernst N, Iglesias A, Dornmair K, Wekerle H, Hohlfeld $\mathrm{R}$ (1995) $\mathrm{T}$ cell receptor repertoire in polymyositis: clonal expansion of autoaggressive $\mathrm{CD}^{+} \mathrm{T}$ cells. J Exp Med 181:1863-1868. doi:10.1084/jem.181.5.1863

18. Bender A, Behrens L, Engel AG, Hohlfeld R (1998) T-cell heterogeneity in muscle lesions of inclusion body myositis. J Neuroimmunol 84:86-91. doi:10.1016/S0165-5728(97)00246-4

19. Hofbauer M, Wiesener S, Babbe H, Roers A, Wekerle H, Dornmair K, Hohlfeld R, Goebels N (2003) Clonal tracking of autoaggressive $\mathrm{T}$ cells in polymyositis by combining laser microdissection, single-cell PCR, and CDR3-spectratype analysis. 
Proc Natl Acad Sci U S A 100:4090-4095. doi:10.1073/pnas. 0236183100

20. Derfuss T, Segerer S, Herberger S, Sinicina I, Hüfner K, Ebelt K, Knaus H-J, Steiner I, Meinl E, Dornmair K, Arbusow V, Strupp M, Brandt T, Theil D (2007) Presence of HSV-1 immediate early genes and clonally expanded T-cells with a memory effector phenotype in human trigeminal ganglia. Brain Pathol 17:389-398. doi:10.1111/j.1750-3639.2007.00088.x

21. Pellkofer HL, Voltz R, Goebels N, Hohlfeld R, Dornmair K (2009) Cross-reactive T-cell receptors in tumor and paraneoplastic target tissue. Arch Neurol 66(5):655-658

22. Schwab N, Bien CG, Waschbisch A, Becker A, Vince GH, Dornmair K, Wiendl H (2009) CD8 ${ }^{+}$T-cell clones dominate brain infiltrates in Rasmussen encephalitis and persist in the periphery. Brain 132(Pt 5):1236-1246

23. Seitz S, Schneider CK, Malotka J, Nong X, Engel AG, Wekerle H, Hohlfeld R, Dornmair K (2006) Reconstitution of paired T cell receptor $\alpha$ - and $\beta$-chains from microdissected single cells of human inflammatory tissues. Proc Natl Acad Sci U S A 103: 12057-12062. doi:10.1073/pnas.0604247103

24. Lefranc M-P, Lefranc G (2001) The T cell receptor facts book. Academic, London, UK

25. Letourneur F, Malissen B (1989) Derivation of a T cell hybridoma variant deprived of functional $\mathrm{T}$ cell receptor $\alpha$ and $\beta$ chain transcripts reveals a nonfunctional $\alpha$-mRNA of BW5147 origin. Eur J Immunol 19:2269-2274. doi:10.1002/eji.1830191214

26. Blank U, Boitel B, Mège D, Ermonval M, Acuto O (1993) Analysis of tetanus toxin peptide/DR recognition by human T cell receptors reconstituted into a murine $\mathrm{T}$ cell hybridoma. Eur $\mathrm{J}$ Immunol 23:3057-3065. doi:10.1002/eji.1830231203

27. Pluschke G, Rüegg D, Hohlfeld R, Engel AG (1992) Autoaggressive myocytotoxic T lymphocytes expressing an unusual $\gamma / \delta$ $\mathrm{T}$ cell receptor. J Exp Med 176:1785-1789. doi:10.1084/ jem.176.6.1785

28. Wiendl H, Malotka J, Holzwarth B, Weltzien HU, Wekerle H, Hohlfeld R, Dornmair K (2002) An autoreactive $\gamma \delta$ TCR derived from a polymyositis lesion. J Immunol 169:515-521

29. Dornmair K, Schneider CK, Malotka J, Dechant G, Wiendl H, Hohlfeld R (2004) Antigen recognition properties of a V $\gamma 1.3 \mathrm{~V} \delta 2$ T-cell receptor from a rare variant of polymyositis. J Neuroimmunol 152:168-175 10.1016/j.jneuroim.2004.03.016

30. Hayday AC (2000) $\gamma \delta \mathrm{T}$ cells: a right time and a right place for a conserved third way of protection. Annu Rev Immunol 18:9751026. doi:10.1146/annurev.immunol.18.1.975

31. O'Brien RL, Roark CL, Jin N, Aydintug MK, French JD, Chain JL, Wands JM, Johnston M, Born WK (2007) $\gamma \delta$ T-cell receptors: functional correlations. Immunol Rev 215:77-88. doi:10.1111/ j.1600-065X.2006.00477.X

32. Chien YH, Konigshofer Y (2007) Antigen recognition by $\gamma \delta \mathrm{T}$ cells. Immunol Rev 215:46-58. doi:10.1111/j.1600-065X. 2006.00470.x

33. Beetz S, Wesch D, Marischen L, Welte S, Oberg HH, Kabelitz D (2008) Innate immune functions of human $\gamma \delta \mathrm{T}$ cells. Immunobiology 213:173-182. doi:10.1016/j.imbio.2007.10.006

34. Sarikonda G, Wang H, Puan KJ, Liu XH, Lee HK, Song YC, Distefano MD, Oldfield E, Prestwich GD, Morita CT (2008) Photoaffinity antigens for human $\gamma \delta \mathrm{T}$ cells. J Immunol 181:7738-7750

35. Fujinami RS, Oldstone MBA (1985) Amino acid homology between the encephalitogenic site of myelin basic protein (MBP) and virus: mechanism for autoimmunity. Science 230:1043-1046. doi:10.1126/science. 2414848

36. Sospedra M, Martin R (2006) Molecular mimicry in multiple sclerosis. Autoimmunity 39:3-8. doi:10.1080/08916930500484922

37. Libbey JE, Mccoy LL, Fujinami RS (2007) Molecular mimicry in multiple sclerosis. Int Rev Neurobiol 79:127-147
38. Van der Bruggen P, Traversari C, Chomez P, Lurquin C, De Plaen E, Van den Eynde B, Knuth A, Boon T (1991) A gene encoding an antigen recognized by cytolytic $\mathrm{T}$ lymphocytes on a human melanoma. Science 254:1643-1647. doi:10.1126/science.1840703

39. Krishnamoorthy G, Saxena A, Mars LT, Domingues HS, Mentele R, Ben-Nun A, Lassmann H, Dornmair K, Kurschus FC, Liblau R, Wekerle H (2009) Myelin specific $T$ cells co-recognize neuronal autoantigen in a transgenic mouse model of multiple sclerosis. Nat Med 15(6):626-632

40. Cresswell P, Ackerman AL, Giodini A, Peaper DR, Wearsch PA (2005) Mechanisms of MHC class I-restricted antigen processing and cross-presentation. Immunol Rev 207:145-157. doi:10.1111/ j.0105-2896.2005.00316.x

41. Vyas JM, Van der Veen AG, Ploegh HL (2008) The known unknowns of antigen processing and presentation. Nat Rev Immunol 8:607-618. doi:10.1038/nri2368

42. Wilson DB, Wilson DH, Schroder K, Pinilla C, Blondelle S, Houghten RA, Garcia KC (2004) Specificity and degeneracy of T cells. Mol Immunol 40:1047-1055. doi:10.1016/j.molimm. 2003.11.022

43. Nino-Vasquez JJ, Allicotti G, Borras E, Wilson DB, Valmori D, Simon R, Martin R, Pinilla C (2005) A powerful combination: the use of positional scanning libraries and biometrical analysis to identify cross-reactive T cell epitopes. Mol Immunol 40:10631074. doi:10.1016/j.molimm.2003.11.005

44. Sospedra M, Martin R (2006) When T cells recognize a pattern, they might cause trouble. Curr Opin Immunol 18:697-703. doi:10.1016/j.coi.2006.09.006

45. Wucherpfennig KW, Allen PM, Celada F, Cohen IR, De Boer R, Garcia KC, Goldstein B, Greenspan R, Hafler D, Hodgkin P, Huseby ES, Krakauer DC, Nemazee D, Perelson AS, Pinilla C, Strong RK, Sercarz EE (2007) Polyspecificity of T cell and B cell receptor recognition. Semin Immunol 19:216-224. doi:10.1016/j. smim.2007.02.012

46. Rosenberg SA (1999) A new era for cancer immunotherapy based on the genes that encode cancer antigens. Immunity 10:281-287. doi:10.1016/S1074-7613(00)80028-X

47. Boon T, Coulie PG, Van den Eynde BJ, Van der Bruggen P (2006) Human $\mathrm{T}$ cell responses against melanoma. Annu Rev Immunol 24:175-208. doi:10.1146/annurev.immunol.24.021605.090733

48. Smith ES, Mandokhot A, Evans EE, Mueller L, Borrello MA, Sahasrabudhe DM, Zauderer M (2001) Lethality-based selection of recombinant genes in mammalian cells: application to identifying tumor antigens. Nat Med 7:967-972. doi:10.1038/ 91017

49. Wong FS, Karttunen J, Dumont C, Wen L, Visintin I, Pilip IM, Shastri N, Pamer EG, Janeway CA (1999) Identification of an MHC class I-restricted autoantigen in type I diabetes by screening an organ-specific cDNA library. Nat Med 5:1026-1031. doi: $10.1038 / 12465$

50. Van Gelder RN, Von Zastrow ME, Yool A, Dement WC, Barchas JD, Eberwine JH (1990) Amplified RNA synthesized from limited quantities of heterogeneous complementary DNA. Proc Natl Acad Sci U S A 87:1663-1667. doi:10.1073/pnas.87.5.1663

51. Meinl E, Krumbholz M, Hohlfeld R (2006) B lineage cells in the inflammatory CNS environment: migration, maintenance, local antibody production and therapeutic modulation. Ann Neurol 59:880-892. doi:10.1002/ana.20890

52. Mathey EK, Derfuss T, Storch MK, Williams KR, Hales K, Woolley DR, Al-Hayani A, Davies SN, Rasband MN, Olsson T, Moldenhauer A, Velhin S, Hohlfeld R, Meinl E, Linington C (2007) Neurofascin as a novel target for autoantibody-mediated axonal injury. J Exp Med 204:2363-2372. doi:10.1084/jem. 20071053

53. Derfuss T, Parikh K, Velhin S, Braun M, Mathey E, Krumbholz M, Kümpfel T, Moldenhauer A, Rader C, Sonderegger P, 
Pöllmann W, Tiefenthaller C, Bauer J, Lassmann H, Wekerle H, Karagogeos D, Hohlfeld R, Linington C, Meinl E (2009) Contactin-2/Tag-1 directed autoimmunity is identified in multiple sclerosis patients and mediates gray matter pathology in animals. Proc Natl Acad Sci U S A 106(20):8302-8307

54. Obermeier B, Mentele R, Malotka J, Kellermann J, Wekerle H, Lottspeich F, Hohlfeld R, Dornmair K (2008) Matching of oligoclonal Ig transcriptomes and proteomes of cerebrospinal fluid in multiple sclerosis. Nat Med 14:688-693. doi:10.1038/ nm1714

55. Wang X, Stollar BD (2000) Human immunoglobulin variable region gene analysis by single cell RT-PCR. J Immunol Meth 244:217-225

56. Brezinschek H-P, Brezinschek RI, Lipsky PE (1995) Analysis of heavy chain repertoire of human peripheral B cells using singlecell polymerase chain reaction. J Immunol 155:190-202

57. Bräuninger A, Küppers R, Spieker T, Siebert R, Strickler JG, Schleiffenbaum B, Rajewsky K, Hansmann M-L (1999) Molecular analysis of single B cells from $\mathrm{T}$ cell rich $\mathrm{B}$ cell lymphoma shows the derivation of the tumor cells from mutating germinal center $\mathrm{B}$ cells and exemplifies means by which immunoglobulin genes are modified in germinal center B cells. Blood 93:2679-2687

58. Wardemann H, Yurasov S, Schaefer A, Young JW, Meffre E, Nussenzweig MC (2003) Predominant autoantibody production by early human B cell precursors. Science 301:1374-1377. doi:10.1126/science.1086907

59. Owens GP, Ritchie AM, Burgoon MP, Williamson RA, Corboy JR, Gilden DH (2003) Single-cell repertoire analysis demonstrates that clonal expansion is a prominent feature of the $\mathrm{B}$ cell response in multiple sclerosis cerebrospinal fluid. J Immunol 171:2725-2733

60. Holliger P, Hudson PJ (2005) Engineered antibody fragments and the rise of single domains. Nat Biotechnol 23:1126-1136. doi: $10.1038 /$ nbt1142

61. Bradshaw EM, Orihuela A, McArdel SL, Salajegheh M, Amato AA, Hafler DA, Greenberg SA, O'Connor KC (2007) A local antigen-driven humoral response is present in the inflammatory myopathies. J Immunol 178:547-556

62. von Büdingen HC, Harrer MD, Kuenzle S, Meier M, Goebels N (2008) Clonally expanded plasma cells in the cerebrospinal fluid of MS patients produce myelin-specific antibodies. Eur J Immunol 38:2014-2023. doi:10.1002/eji.200737784

63. Owens GP, Bennett JL, Lassmann H, O'Connor KC, Ritchie AM, Shearer A, Lam C, Yu XL, Birlea M, DuPree C, Williamson RA, Hafler DA, Burgoon MP, Gilden D (2009) Antibodies produced by clonally expanded plasma cells in multiple sclerosis CSF. Ann Neurol 65(6):639-649

64. Robinson WH, DiGennaro C, Hueber W, Haab BB, Kamachi M, Dean EJ, Fournel S, Fong D, Genovese MC, De Vegvar HEN,
Skriner K, Hirschberg DL, Morris RI, Muller S, Pruijn GJM, Van Venrooij WJ, Smolen JS, Brown PO, Steinman L, Utz PJ (2002) Autoantigen microarrays for multiplex characterization of autoantibody responses. Nat Med 8:295-301. doi:10.1038/nm0302-295

65. Kanter JL, Narayana S, Ho PP, Catz I, Warren KG, Sobel RA, Steinman L, Robinson WH (2006) Lipid microarrays identify key mediators of autoimmune brain inflammation. Nat Med 12:138 143. doi: $10.1038 / \mathrm{nm} 1344$

66. Quintana FJ, Farez MF, Viglietta V, Iglesias AH, Merbl Y, Izquierdo G, Basso AS, Khoury SJ, Lucchinetti CF, Cohen IR, Weiner HL (2008) Antigen microarrays identify unique serum autoantibody signatures in clinical and pathologic subtypes of multiple sclerosis. Proc Natl Acad Sci USA 105:18889-18894. doi:10.1073/pnas.0806310105

67. Jäger D, Taverna C, Zippelius A, Knuth A (2004) Identification of tumor antigens as potential target antigens for immunotherapy by serological expression cloning. Cancer Immunol Immunother 53:144-147. doi:10.1007/s00262-003-0470-z

68. Kabat EA, Moore DH, Landow H (1942) An electrophoretic study of the protein components in cerebrospinal fluid and their relationship to the serum proteins. J Clin Invest 21:571-577. doi:10.1172/JCI101335

69. Qin Y, Duquette P, Zhang Y, Poole R, Antel JP (1998) Clonal expansion and somatic hypermutation of $\mathrm{V}_{\mathrm{H}}$ genes of $\mathrm{B}$ cells from cerebrospinal fluid in multiple sclerosis. J Clin Invest 102:10451050. doi: $10.1172 / \mathrm{JCI} 3568$

70. Owens GP, Kraus H, Burgoon MP, Smith-Jensen T, Devlin ME, Gilden DH (1998) Restricted use of $\mathrm{V}_{\mathrm{H}} 4$ germline segments in an acute multiple sclerosis brain. Ann Neurol 43:236-243. doi:10.1002/ana.410430214

71. Baranzini SE, Jeong MC, Butunoi C, Murray RS, Bernard CCA, Oksenberg JR (1999) B cell repertoire diversity and clonal expansion in multiple sclerosis brain lesions. J Immunol 163:5133-5144

72. Colombo M, Dono M, Gazzola P, Roncella S, Valetto A, Chiorazzi N, Mancardi GL, Ferrarini M (2000) Accumulation of clonally related $\mathrm{B}$ lymphocytes in the cerebrospinal fluid of multiple sclerosis patients. J Immunol 164:2782-2789

73. Monson NL, Brezinschek H-P, Brezinschek R, Mobley A, Vaughan GK, Frohman EM, Racke MK, Lipsky PE (2005) Receptor revision and atypical mutational characteristics in clonally expanded B cells from the cerebrospinal fluid of recently diagnosed multiple sclerosis patients. J Neuroimmunol 158:170 181. doi:10.1016/j.jneuroim.2004.04.022

74. Hohlfeld R, Wekerle H (2004) Autoimmune concepts of multiple sclerosis as a basis for selective immunotherapy: from pipe dreams to (therapeutic) pipelines. Proc Natl Acad Sci U S A 101 (Suppl 2):14599-14606. doi:10.1073/pnas.0404874101 